\title{
Smoking cessation in clinical practice: predictors of six- month continuous abstinence in a sample of Greek smokers
}

\section{*Afroditi K Boutou a, Eleni A Tsiatab, Athanasia Patakac, Paschalina K Kontoud, Georgia G Pitsioub, Paraskevi Argyropouloue}

\footnotetext{
a Research fellow, Respiratory Failure Unit, Aristotle University, "G. Papanikolaou" Hospital, Thessaloniki, Greece

b Pulmonologist, Respiratory Failure Unit, Aristotle University, "G. Papanikolaou” Hospital, Thessaloniki

c Pulmonology resident, Department of Pneumonology and Intensive Care Unit, Democritus University of Thrace, General Hospital of Alexandroupolis, Alexandroupolis, Greece

"Pulmonology resident, Respiratory Failure Unit, Aristotle University, "G. Papanikolaou” Hospital, Thessaloniki

e Professor of Pulmonology, Respiratory Failure Unit, Aristotle University, "G. Papanikolaou” Hospital, Thessaloniki
}

Received 13th May 2007; accepted 23rd October 2007

\begin{abstract}
Aim: To identify the predictors of six-month continuous abstinence among Greek smokers treated in a Smoking Cessation Clinic, emphasising the role of sleep disturbance on the outcome.

Methods: A nested case-control design was used. Patients who attended the Smoking Cessation Clinic between November 2004 and October 2005, and who completed six months of follow-up, constituted the final study population ( $\mathrm{N}=285$ ). The patients were separated into two groups - those who managed to quit smoking and those who didn't. The cessation method included pharmacotherapy, oneto-one behavioral counselling, and follow-up by telephone communication.

Results: Among various baseline characteristics examined, multivariate regression analysis indicated that the time to first cigarette after awakening, and use of bupropion, independently predicted abstinence, while awakening during the night was negatively associated with abstinence.

Conclusion: These multivariate factors, which can positively or negatively affect the outcome, should be taken into account so that smoking cessation treatment can be individualised.

(c) 2008 General Practice Airways Group. All rights reserved.

AK Boutou, et al. Prim Care Resp J 2008; 17(1): 32-38.

doi:10.3132/pcrj.2008.00009
\end{abstract}

Keyw ords smoking cessation, predictors, six-month continuous abstinence, clinical practice

\section{Introduction}

Cigarette smoking is a major cause of lung cancer, cardiovascular disease and chronic obstructive pulmonary disease (COPD), resulting in 1.2 million deaths annually according to the World Health Organization (WHO). ${ }^{1}$ Since tobacco use is the single largest avoidable cause of death and disability in developed countries, ${ }^{2}$ achieving life-long abstinence is an important public health goal. With natural quit rates being around $7 \%,{ }^{3}$ smoking cessation intervention programs are of interest if they can increase the rates of abstinence. Nicotine replacement therapy (NRT) and bupropion SR, in combination with behavioral counselling, are recommended by WHO as effective methods to treat tobacco dependence among motivated smokers. ${ }^{1}$

An important clinical aspect related to smoking cessation is the identification of factors which can predict the outcome of an attempt to quit; at present, no accurate and consistent determinants of abstinence have been found. Demographic parameters, ${ }^{4,5}$ socio-economic characteristics, ${ }^{4,5}$ psychological factors, ${ }^{6}$ smoking history, ${ }^{4}$ and severity of dependence ${ }^{6,7}$ have

\footnotetext{
* Corresponding author: 36 St Vasileiou str, Kalamaria, 55133, Thessaloniki, Greece.

Tel: +30 2310350178 E-mail: afboutou@yahoo.com
} 
been studied both in aided and unaided smoking cessation, but results are still conflicting. Moreover, although sleeprelated symptoms of nicotine withdrawal may make smoking cessation more difficult and relapses more frequent, data on their predictive value on successful abstinence are limited. ${ }^{8}$

A survey that assessed the anti-smoking climate in Poland and other European Union countries, indicated the existence of significant dissimilarities both on quitting behavior and attitudes relating to smoking among their resident smokers. ${ }^{9}$ These differences suggest that the predictors of aided smoking cessation should be individually assessed in smoker populations of different countries, particularly in real-life clinical practice. With smoking-related mortality being higher in Greece than in the rest of the European Union (260.14 per 100,000 deaths versus 229.14 per 100,000 deaths in 2000$)^{10}$ and the smoking prevalence rising above $34 \%$ in some areas of this country, ${ }_{11}^{11}$ investigation into the factors that can affect smoking cessation outcome during clinical practice is of great importance.

Therefore, the objective of the present study was to determine, for the first time, the predictors of continuous sixmonth abstinence among Greek smokers treated in a Smoking Cessation Clinic (SCC), emphasising the role of sleep-related symptoms secondary to nicotine withdrawal.

\section{Methods}

\section{Study design}

The present study used a nested case-control design. The initial cohort consisted of 408 smokers - $240(58.8 \%)$ men and $168(41.2 \%)$ women - aged 18 and over, who didn't have a history of psychiatric disorder, used no other type of tobacco than cigarettes, were self-referred to the SCC, and underwent smoking cessation therapy from 1st November 2004 until 31st October 2005. Subjects who completed six months of follow-up were the study population, and they were separated into two groups - those who quit smoking ("cases") and those who failed to quit ("controls") - see Figure 1. A total of 285 subjects $(175(61.4 \%)$ men and 110 $(38.6 \%)$ women) fulfilled the above criteria and were included in the analysis. The comparison between the final study population and the initial cohort showed no significant differences in any of the characteristics studied (data not shown). All subjects participated in the study after providing informed consent, and the project was approved by the institution's ethical committee.

\section{Subject evaluation}

Pre-treatment Questionnaires: Subjects were given 15 minutes to complete a) the eight-item Fagerstrom Tolerance Questionnaire (FTQ $)^{12}$ and b) a questionnaire which assessed the following: demographic data; information on smoking history and previous quit attempts; desire to stop smoking; self-confidence in quitting; ability to recognise and avoid
Figure 1. Study flow chart: from the $\mathbf{4 0 8}$ patients who attended the SCC and were willing and eligible for the study (initial cohort), 285 completed six months of

follow-up and constituted the final study population.

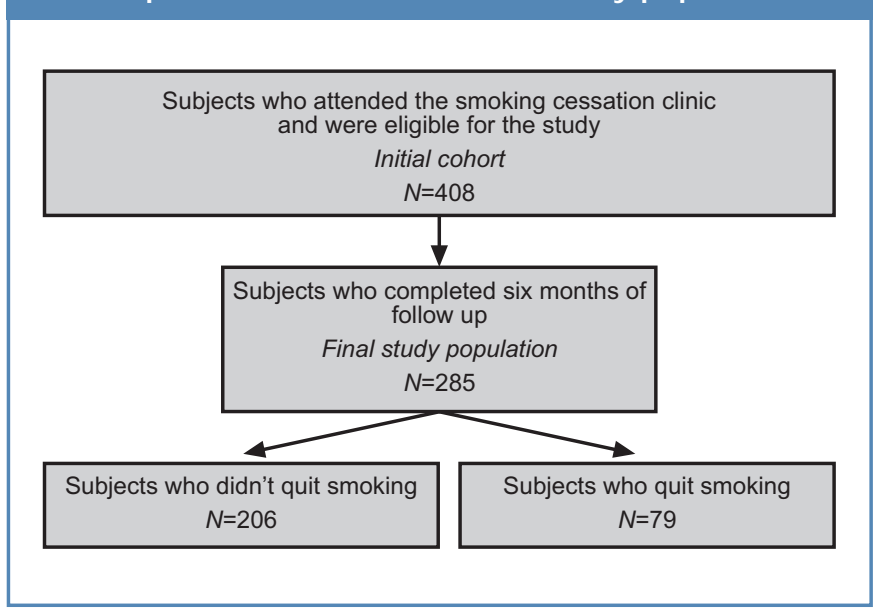

certain situations/temptations to smoke; and intention to set a "target date" for smoking cessation (Tables 1 and 2).

M edical session: Treating physicians examined the subjects and recorded their exhaled carbon monoxide (CO) levels. Bupropion SR (150 mg once daily for 6 days, increasing on the 7th day to $150 \mathrm{mg}$ twice daily) was prescribed to all subjects, unless the presence of known contraindications dictated the use of NRT (transdermal 16-hour patches of 15, 10 and $5 \mathrm{mg}$ dose, or nicotine gum of $2 \mathrm{mg}$ dose), according to guidelines. Total duration of prescribed therapy was eight weeks and a target quit date for all participants was set within two weeks from the medical session. ${ }^{3,13,14}$ Patients also received a one-to-one 30-minute behavioral cessation intervention in a structured form, self-help leaflets for smoking cessation, and diaries to record the initiation of treatment, target quit-day and number of cigarettes smoked daily, during the whole six-month period.

Follow-up: Follow-up included telephone calls once a week during the first month of cessation and once every two weeks during the second month. Follow-up calls have been previously described to be effective for long-term smoking cessation. ${ }^{6,15}$ Telephone calls were prescheduled at the medical session, were made by the smoker to the examining physician, and had the form of brief (lasting three minutes) counselling. During telephone contact on the second day of abstinence, subjects were asked to rate the intensity of nine DSM-IV nicotine withdrawal symptoms, using a 0-4 scale ${ }^{16}$ (Table 2). Six months after the medical session all smokers were contacted by telephone in order to identify those who had quit smoking. Smoking cessation was defined as six-month continuous abstinence, lasting from the scheduled quitting day until the moment of telephone contact. 
Table 1. Baseline characteristics of the study population and univariate predictors of continuous six-month abstinence (categorical and ordinal variables).

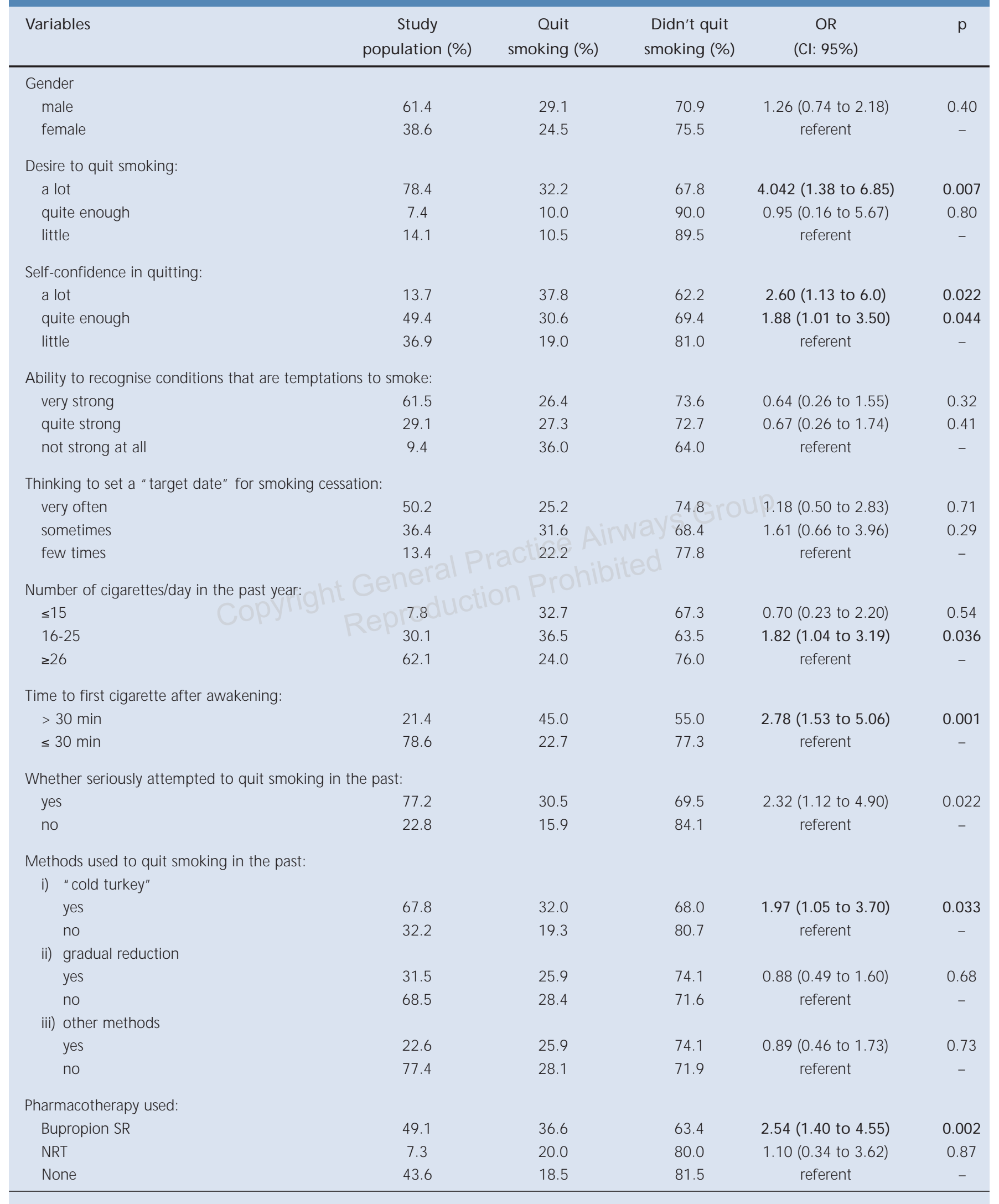


Table 2. Baseline characteristics of the study population and univariate predictors of continuous six-month abstinence (continuous variables).

\begin{tabular}{|c|c|c|c|c|c|}
\hline Variables & $\begin{array}{c}\text { Study } \\
\text { population }\end{array}$ & $\begin{array}{c}\text { Quit } \\
\text { smoking }\end{array}$ & $\begin{array}{l}\text { Didn't quit } \\
\text { smoking }\end{array}$ & $\begin{array}{c}\text { Difference between } \\
\text { means }(95 \% \mathrm{Cl})\end{array}$ & $\mathrm{p}$ \\
\hline Age (years) & $44.5 \pm 11.2$ & $42.3 \pm 11.0$ & $45.3 \pm 11.2$ & $-2.96(-5.86$ to -0.60$)$ & 0.046 \\
\hline Age started regularly smoking (years) & $19.4 \pm 5.2$ & $19.1 \pm 5.1$ & $19.5 \pm 5.3$ & $-0.40(0.70$ to -1.73$)$ & 0.61 \\
\hline Total smoking duration (years) & $25.0 \pm 10.5$ & $23.1 \pm 10.2$ & $25.7 \pm 10.5$ & $-2.60(1.39$ to -5.29$)$ & 0.07 \\
\hline \multicolumn{6}{|l|}{ DSM -IV nicotine withdrawal symptom scale: } \\
\hline i) intense desire to smoke & $2.3 \pm 1.5$ & $2.2 \pm 1.5$ & $2.4 \pm 1.5$ & $-0.20(-0.57$ to 0.24$)$ & 0.43 \\
\hline ii) depressive or dysphoric mood & $0.8 \pm 1.2$ & $0.6 \pm 1.1$ & $0.9 \pm 1.3$ & $-0.30(-0.62$ to 0.06$)$ & 0.10 \\
\hline iii) insomnia & $0.8 \pm 1.3$ & $0.6 \pm 1.1$ & $0.9 \pm 1.3$ & $-0.30(-0.63$ to 1.00$)$ & 0.15 \\
\hline vii) difficulty in concentrating & $1.5 \pm 1.4$ & $1.4 \pm 1.4$ & $1.5 \pm 1.4$ & $-0.10(-0.44$ to 0.34$)$ & 0.80 \\
\hline viii)restlessness & $2.0 \pm 1.4$ & $2.0 \pm 1.4$ & $1.9 \pm 1.4$ & $0.10(-0.34$ to 0.46$)$ & 0.76 \\
\hline ix) increased appetite & $1.9 \pm 1.4$ & $1.9 \pm 1.5$ & $1.8 \pm 1.4$ & $0.10(-0.35$ to 0.46$)$ & 0.78 \\
\hline FTQ & $7.3 \pm 1.8$ & $7.0 \pm 1.7$ & $7.4 \pm 1.8$ & $0.40(-0.88$ to 0.04$)$ & 0.07 \\
\hline
\end{tabular}

Moreover, subjects were asked about the pharmacotherapy they had used and its total duration. Three attempts to contact every subject were made in total, at different hours of the day and days of the week (weekends and holidays included). If there were three unsuccessful attempts, the subject was excluded from the final study population.

Statistical analysis

Statistical analysis was performed using the SPSS (Statistical Package for Social Sciences) version 11.5 for W indows 2000 XP (SPSS Inc., Chicago, IL, U.S.A.). Continuous variables are presented as mean value \pm 1 standard deviation (mean \pm SD) and categorical variables as $\%$ percentage values.

Bupropion SR reaches steady-state plasma concentration during the second week of treatment, ${ }^{14}$ while for NRT the 2week minimum timeframe has been previously used so that symptoms of nicotine deprival are effectively controlled. ${ }^{17}$ This is why patients who received pharmacotherapy for less than two weeks were included in the category of those who didn't receive any medication, and total duration of pharmacotherapy was calculated only for subjects who received medication for at least two weeks. The comparison between subjects who received and those who didn't receive any medication showed no significant differences in their baseline characteristics (data not shown).

Predictors of outcome were investigated with univariate and multivariate analysis. In the first part, the group of subjects who quit smoking was compared to the group of subjects who didn't quit for the total number of baseline characteristics, using $x^{2}$ test for categorical variables and independent samples Student's t-test for continuous variables. The effect of categorical variables on abstinence was assessed by estimating the odds ratios (ORs) and their corresponding 95\% confidence intervals $(95 \% \mathrm{Cls})$. Each variable's last subgroup was used as the reference, against which ORs for the rest of the subgroups were calculated. The effect of continuous variables on abstinence was assessed using differences between means (DMs) and their corresponding 95\% Cls. In the second part, all variables previously identified as having an influence on sixmonth continuous abstinence were included into a stepwise multivariate logistic regression analysis. Adjusted ORs and their corresponding $95 \%$ Cls were used to describe a variable's effect as an independent predictor of six-month continuous abstinence; all categorical variables were interpreted in terms of the left-out reference category.

\section{Results}

Pretreatment and treatment characteristics of the subjects are presented in Table 1 and Table 2. The overall continuous sixmonth abstinence rate was $27.4 \%$. Although bupropion SR and NRT were prescribed to $87.0 \%$ and $12.3 \%$ of patients, respectively, only $56.4 \%$ of the study population eventually received pharmacotherapy. Treatment compliance was $56.3 \%$ 
Table 3. Multivariate predictors of continuous six-month abstinence.

\begin{tabular}{|c|c|c|c|}
\hline Variables & $\begin{array}{c}\text { Adjusted } \\
\text { OR }\end{array}$ & $\begin{array}{c}95 \% \mathrm{Cl} \\
\text { for Adjusted OR }\end{array}$ & $\mathrm{p}$ \\
\hline \multicolumn{4}{|c|}{ Time to first cigarette after awakening } \\
\hline$>30 \mathrm{~min}$ & 5.033 & 1.57 to 8.10 & 0.006 \\
\hline$\leq 30 \mathrm{~min}$ & referent & - & - \\
\hline Awakening during night & 0.607 & 0.39 to 0.95 & 0.029 \\
\hline \multicolumn{4}{|l|}{ Pharmacotherapy used: } \\
\hline Bupropion SR & 2.886 & 1.05 to 7.90 & 0.039 \\
\hline NRT & 2.95 & 0.50 to 17.45 & 0.23 \\
\hline None & referent & - & - \\
\hline
\end{tabular}

for bupropion SR and $60.0 \%$ for NRT. Bupropion SR was used for $4.8 \pm 2.3$ weeks and NRT for $6.1 \pm 3.6$ weeks; however, the duration of bupropion use didn't differ significantly $(p=0.7)$ between subjects who quit and those who didn't quit smoking. Subjects made $3.2 \pm 1.6$ telephone follow-up calls; the number of calls didn't differ $(p=0.5)$ between those who quit and those who didn't quit smoking.

Univariate analysis of predictors of six-month abstinence

Older age, the desire to quit ('a lot' versus 'little'), selfconfidence in quitting ('a lot' versus 'little' and 'quite enough' versus 'little'), the number of cigarettes smoked per day (1625 versus $\geq 26$ ), time to first cigarette after awakening being longer than 30 minutes, existence of previous serious quit attempts, use of the "cold turkey" method to quit smoking in the past, and bupropion SR use (versus no pharmacotherapy), were found to be positively associated with quitting.

Awakening during the night was the only parameter found to be negatively associated with six-month continuous abstinence - see Tables 1 and 2 .

Multivariate analysis of predictors of six-month abstinence

Because of the strong correlation between "previous serious attempt to quit" and use of the "cold turkey" method to quit, only the variable with the highest $\mathrm{OR}$ (previous serious attempt to quit) was included in the multivariate model.

The final stepwise logistic regression model identified the following three variables as independent predictors of the smoking cessation intervention outcome: time to first cigarette after awakening being longer than 30 minutes; bupropion SR use versus no pharmacotherapy use; and awakening during the night (Table 3 ). The first two variables predict a successful outcome, while awakening during the night constitutes a predictor of six-month abstinence failure.

\section{Discussion}

The present study is the first one to identify the determinants of continuous six-month abstinence for Greek smokers following treatment in a SCC in real-life clinical practice. Bupropion SR use, and the time to first cigarette after awakening being longer than 30 minutes, independently predicted a successful outcome, confirming previous data. However, this is the only study, to the best of our knowledge, which indicates that awakening during the night is an independent predictor of continuous abstinence failure.

In this study, the use of bupropion SR was a significant predictor of smoking cessation; drug administration increased the odds of six-month abstinence by 2.89 times, compared to no pharmacotherapy use. A Cochrane Library meta-analysis of 5 double-blind clinical trials estimated bupropion's odds ratio for smoking cessation to be $2.73 .{ }^{18}$ The present study indicates that the real-life effectiveness of bupropion is similar to the one observed in the active drug group of placebocontrolled clinical trials. However, it is quite interesting that subjects who quit used bupropion for an average period of 5.1 weeks; that is three weeks less from what is recommended. ${ }^{12}$ M oreover, although the use of bupropion SR for at least two weeks independently predicted abstinence, further prolongation of its administration didn't seem to increase success rates, since duration of use didn't differ significantly among those subjects who remained abstinent and those who didn't. Greater length of time on bupropion treatment has been previously associated with increased odds of smoking cessation; ${ }^{12}$ the present clinical setting, though, didn't confirm this finding.

Time to first cigarette after awakening, a common measure of nicotine dependence, was found to be the most significant predictor of cessation; lighting the first cigarette after at least 30 minutes increased the odds of abstinence by about 5 times, confirming previous findings that a long time to the first cigarette may predict both long-term ${ }^{5}$ and medium-term ${ }^{16}$ abstinence. The role of nicotine dependence as a risk factor for smoking following bupropion treatment ${ }^{7}$ or various non-bupropion therapies ${ }^{19}$ is well known. However, 
there are conflicting results as to which specific variables may predict more accurately the severity of dependence and the successful outcome. Fagerstrom score and daily consumption of cigarettes indicated a predictive value in some studies,, 5 whereas in others they were not associated with the outcome $\mathrm{e}^{20.22}$ - as is the case in the present study.

Perhaps the most important finding of this study is that awakening during the night was found to be strongly associated to the outcome; one unit of increase in the symptom intensity score decreased the odds of six-month abstinence by $39 \%$. Sleep disturbance, mostly insomnia, can be an adverse effect of smoking cessation pharmacotherapy; ${ }^{17}$ however, awakening during the night remained a significant predictor of abstinence even after pharmacotherapy use was entered in the stepwise multivariate model, indicating that the first is an independent predictor of the outcome. Nicotine deprival has been shown to increase significantly the number of relative arousals, ${ }^{23}$ and nocturnal awakening has been reported to be present in up to $39 \%$ of cases of smokers deprived of nicotine. ${ }^{24}$ Given the fact that sleep disorders have been associated with increased relapses among smokers, they should be taken into account in smoking cessation programs, since relieving them may increase smokers' odds to remain abstinent. ${ }^{9}$ Moreover, this study's findings indicate that sleep pattern during smoking cessation and abstinence should be further investigated using nocturnal polysomnography. This could address a major gap in the literature, since the existing data on laboratory-based assessment of the effects of smoking cessation on sleep is very limited. ${ }^{25}$

The strength of this study includes its prospective nested case-control design. Interviewer biases were minimised, since the investigator was blinded to the outcome when recording baseline characteristics of the participants. Recall bias were also minimised, since subjects gave information about their attitude towards quitting and their smoking behavior just before attempting to quit. The same applies to nicotine withdrawal symptoms, since they were recorded during the second day of abstinence and not retrospectively. Moreover, successful outcome and predictors of abstinence were assessed for the total number of the study population, regardless of the kind of therapy used and the duration of medication, in order for the findings to represent the reality of every-day clinical practice.

As the study was conducted in an outpatient setting and follow-up relied on telephone communication, certain measurements were not feasible and could be considered as limitations of this study. Several authors have evaluated the potential disparity between self-reported results and those obtained by objective measures of the exhaled CO level. Findings have varied, depending on the study population. ${ }^{22}$
However, a meta-analysis of 51 comparisons between selfreported behavior and biochemical measures indicated that self-reports were accurate in most studies. ${ }^{26}$ Moreover, selfreporting has been described as a useful tool, not only since it is less expensive, but also since it it is more accessible than biochemical validation. ${ }^{27}$

The lack of objective measurement of adherence constitutes another limitation. The use of automated pill counters or blood levels can provide accurate estimates of medication adherence, ${ }^{28,29}$ but this was not the issue in this study, since the objective was to assess the intervention's effectiveness in everyday practice, without reproducing the "controlled environment" of a clinical trial. There was also an effort to minimise "recall bias" of the subjects, by prompting them to complete their diaries on an everyday basis and to keep them until follow-up was completed. Effectiveness of NRT as an aid for smoking cessation has been repeatedly indicated; a Cochrane Library review of 89 trials of various types of nicotine medications calculated an odds ratio of 1.74 for all forms of NRT. ${ }^{30}$ However, the present study failed to indicate an association between NRT use and six-month abstinence, possibly due to the small number of subjects who underwent nicotine medication treatment.

\section{Conclusions}

The variables that independently predicted continuous sixmonth abstinence among Greek smokers treated in a SCC were the time to first cigarette after awakening being longer than 30 minutes and use of bupropion SR for at least two weeks. Awakening during the night was found to be a negative predictor of the outcome. The presence or absence of these predictors should always be examined during smoking cessation interventions, so that smokers who are at higher or lower "risk" of failing abstinence can be identified early. This could lead to individualised treatments with more intensive interventions and closer follow-up of those who are more likely to fail. Future studies on different populations, including laboratory assessment of the impact of smoking cessation on sleep, are needed to increase further our knowledge in this field.

\section{Conflict of interest declaration}

None to declare.

\section{References}

1. Raw M, Anderson P, Batra A, et al. WHO European evidence recommendations on the treatment of tobacco dependence. World Health Organization European Partnership Project to Reduce Tobacco Dependence. Tob Control 2002;11:44-6.

2. Edwards R. The problem of tobacco smoking. BMJ 2004;328:217-19.

3. The Tobacco Use and Dependence Clinical Practice Guideline Panel, Staff, and Consortium Representatives. A clinical practice guideline for treating tobacco use and dependence. A US Public Health Service Report. JAM A 2000;283:3244-54.

4. West R, M cEwen A, Bolling K, Owen L. Smoking cessation and smoking patterns 
in the general population: a 1-year follow-up. Addiction 2001;96:891-902.

5. Hyland A, Li Q, Bauer JE, Giovino GA, Steger CK, Cummings M. Predictors of cessation in a cohort of current and former smokers followed over 13 years. Nicotine Tob Res 2004;6(3):S363-9.

6. Swan GE, Jack LM, Curry S, et al. Bupropion SR and counselling for smoking cessation in actual practice: Predictors of outcome. Nicotine Tob Res 2003:5(6):911-21.

7. Hurt RD, Wolter TD, Rigotti N, et al. Bupropion for pharmacologic relapse prevention to smoking: predictors of outcome. Addict Behav 2002;27:493507

8. Underner M, Paraquereau J, Meurice JC. Cigarette smoking and sleep disturbance. Rev Mal Respir 2006;23(3):6S67-6S77.

9. Fagerstrom $\mathrm{K}$, Boyle $\mathrm{P}$, Kunze $\mathrm{M}$, Zatonski W. The anti-smoking climate in EU countries and Poland. Lung Cancer 2002;32:1-5.

10. European health for all database (EHF-AD). World Health Organization Regional Office For Europe, updated: January 2007. Available at: http://data.euro.who.int/hfadb/.

11. Sichletidis LT, Chloros D, Tsiotsios I, et al. High prevalence of smoking in Northern Greece. Prim Care Resp J 2006;15:92-7. doi:10.1016/j.pcrj.2006. 01.004

12. Fagerström KO. M easuring degree of physical dependence to tobacco smoking with reference to individualization of treatment. Addict Behav 1978;3:235-41.

13. National Advisory Comittee on Health and Disability (National Health Comittee), 2002. Guidelines for Smoking Cessation. Revised, May 2002, Wellington, New Zealand. Available at: http://www.nzgg.org.nz/guidelines/ 0025/Smoking_Cessation_full.pdf.

14. M artínez-Raga J, Keaney F, Sutherland G, Perez-Galvez B, Strang J. Treatment of nicotine dependence with bupropion SR: review of its efficacy, safety and pharmacological profile. Addict Biol 2003;8:13-21.

15. Argyropoulou P, Pataka A, Pitsiou G, Zisi P, Manolakoglou N, Kontakiotis T. [abstract] Eur Respir] 2005;26(Suppl 49):388s.

16. Diagnostic and statistical manual of mental disorders, 4th ed.: DSM-IV. Washington, D.C.: American Psychiatric Association, 1994.

17. Steinberg MB, Foulds J, Richardson DL, Burke MV, Shah P. Pharmacotherapy and smoking cessation at a tobacco dependence clinic. Prev Med 2006;42:114-19.
18. Hays JT, Hurt RD, Rigotti NA, et al. Sustained-release bupropion for pharmacologic relapse prevention after smoking cessation. A randomized, controlled trial. Ann Intern Med 2001;135(6):423-33.

19. Ockene JK, Emmons KM, Mermelstein RJ, Perkins KA. Relapse and maintenance issues of smoking cessation. Health Psychol 2000;19:17-31.

20. Kenford SL, Fiore MC, Jorenby DE, Smith SS, Wetter D, Baker TB. Predicting smoking cessation. Who will quit with and without the nicotine patch. JAMA 1994;271(8):589-94.

21. Abdullah AS, Lam TH, Chan SS, Hedley AJ. Smoking cessation among Chinese young smokers: does gender and age difference matters and what are the predictors? Addict Behav 2006;31:913-21.

22. Nerin I, Novella P, Crucelaegui A, Beamonte A, Sobradiel N, Cargallo P. Predictors of success at 6 -months follow up for smokers treated at a smoking cessation clinic. Arch Bronconeumol 2004;40(12):558-62.

23. Prosise GL, Bonnet MH, Berry RB, Dickel MJ. Effects of abstinence from smoking on sleep and daytime sleepiness. Chest 1994;105(4):1136-41.

24. Hughes JR, Higgins ST, Bickel WK. Nicotine withdrawal versus other drug withdrawal syndromes: Similarities and dissimilarities. Addiction 1994 89:1461-70

25. Colrain IM, Trinder J, Swan GE. The impact of smoking cessation on objective and subjective markers of sleep: Review, synthesis, and recommendations. Nicotine Tob Res 2004;6(6):913-25.

26. Patrick DL, Cheadle A, Thompson DC, Diehr P, Koepsell T, Kinne S. The validity of self-reported smoking: a review and meta-analysis. Am J Public Health 1994;84(7):1086-93.

27. Rohren CL, Crogan IT, Hurt RD, Kenneth PO, Marusic Z, McClain FL. Predicting smoking cessation outcome in a medical centre from stage of readiness: contemplation versus action. Prev M ed 1994;23:335-44.

28. Farmer KC. Methods for measuring and monitoring medication regimen adherence in clinical trials and clinical practice. Clin Ther 1999;21(6):1074-90.

29. Vitolins MZ, Rand CS, Rapp SR, Ribisl PM, Sevick MA. Measuring adherence to behavioural and medical interventions. Control Clin Trials 2000;21(5):188S-194S.

30. Lancaster T, Stead L, Silagy C, Sow den A. Effectiveness of interventions to help people stop smoking: findings from the Cochrane Library. Cochrane Tobacco Addiction Review Group. BMJ 2000;321:355-8.

Available online at http://w ww.thepcrj.org 